\title{
Linking Delinquency and Personal Identity Formation Across Adolescence: Examining Between- and Within-Person Associations
}

\author{
Natalie Mercer \\ Utrecht University \\ Susan Branje \\ Utrecht University
}

\author{
Elisabetta Crocetti \\ University of Bologna
}

\author{
Pol van Lier \\ Erasmus University Rotterdam
}

\author{
Wim Meeus \\ Utrecht University and Tilburg University
}

\begin{abstract}
Adolescent delinquency and identity formation have both been described in relation to the confusion, doubt, and need for individuation and autonomy faced by adolescents. While theoretical conceptualizations (e.g., Erikson, 1968; Moffitt, 1993) suggest that delinquency and identity formation might be developmentally intertwined across adolescence, this link had yet to be longitudinally examined. This study tested whether delinquency and identity are related and whether we could determine a developmental order considering both between- and within-person associations across adolescence. We examined these associations in a multi-informant sample of 497 Dutch adolescents followed for 5 annual waves from age 14-18. Between-person cross-lagged models showed that adolescents who scored higher on delinquency relative to their peers, scored lower on commitment and higher on reconsideration, 1 year later. Within-person cross-lagged models showed that when adolescents reported above their own average on delinquency, they reported decreased commitment and increased reconsideration 1 year later. Additionally, within-persons, when adolescents reported an increase in in-depth exploration compared with their own average they reported decreased delinquency 1 year later. From these results we can conclude that delinquency and personal identity are indeed related across adolescence. Experimenting with delinquency hampers identity formation by increasing reconsideration and decreasing commitment. Within-person results suggest that interventions tailored to increase in-depth exploration in adolescents may help to prevent adolescent delinquency.
\end{abstract}

Keywords: personal identity formation, delinquency, adolescence, between-persons, within-persons, longitudinal

There are good reasons to assume that delinquency and personal identity formation may be developmentally intertwined. Most adolescents engage in some form of delinquency or rule-breaking (Moffitt, Caspi, Harrington, \& Milne, 2002) and for many adolescents delinquency is thought to be an attempt to evoke more autonomy or an adultlike status (e.g., Chen, 2010) in response to the role ambiguity brought about by the discrepancy between their social and biological age (Moffitt, 1993). At the same time and relatedly, the most important developmental task during adolescence is to individuate from

Natalie Mercer, Research Centre Adolescent Development, Utrecht University; Elisabetta Crocetti, Department of Psychology, University of Bologna; Susan Branje, Research Centre Adolescent Development, Utrecht University; Pol van Lier, Department of Pedagogical Science, Erasmus University Rotterdam; Wim Meeus, Research Centre Adolescent Development, Utrecht University, and Department of Developmental Psychology, Tilburg University.

Correspondence concerning this article should be addressed to Natalie Mercer, Heidelberglaan 1, Utrecht, the Netherlands, 3584 CS. E-mail: n.c.mercer@uu.nl childhood identifications to form a stable personal identity (Erikson, 1950; Marcia, 1966). Therefore, in this study we used two theories of adolescent delinquency, the developmental taxonomy (Moffitt, 1993) and social control theory (Hirschi, 1969), to link adolescent delinquency to adolescent identity formation as developed from Erikson's (1950, 1968) theory of psychosocial development.

Additionally, while previous research has focused on betweenperson differences in the relation between delinquency and identity, this study tested both between- and within-person relations between delinquency and identity. Delinquency and identity theories refer to processes occurring both between and within adolescents, therefore both approaches should be incorporated to comprehensively test this theoretical link. Between persons, the relation between variables is relative to that of other adolescents (i.e., rank-order stability), and within persons, the relation between variables is relative to fluctuations within an adolescent (i.e., more akin to causal processes). By including both between- and withinperson associations we aimed to provide a more complete overview of the developmental interplay between delinquency and identity development. 


\section{Linking Delinquency and Identity Theories}

In Moffitt's (1993) description of adolescence, the challenges of the maturity gap and adolescents' need for autonomy and independence, runs parallel to Erikson's (1968) expectations of adolescents stuck in a role vacuum, letting go of childhood identifications while trying to forge their own commitments, in the process of developing their own personal identities. Additionally, Hirschi's (1969) expectation that weakened bonds or attachments can lead to delinquency corresponds with Erikson's expectations that adolescents who struggle to find meaningful commitments experience difficulties in successfully forming their own identity. With these conceptual similarities, it seems plausible that delinquency and the process of identity formation may be developmentally intertwined. To further delineate this link we describe delinquency and identity theories in more detail below.

\section{Adolescent Delinquency Theory}

A starting point for the plausible link between adolescent delinquency and adolescent identity formation is the fact that the number of people who participate in delinquency sharply increases from early-to-middle adolescence and subsequently decreases from middle-to-late adolescence (Farrington, 1986). To explain this temporary rise in delinquency, in her developmental taxonomy, Moffitt (1993) hypothesized that delinquency confined to adolescence is motivated by the developmental need for autonomy and independence which arise from the role ambiguity caused by a discrepancy between biological and social maturation (i.e., the maturity gap). For example, adolescents are biologically adult, yet are asked to delay some of the most positive aspects of adulthood: For the most part, adolescents remain financially and socially dependent on their parents and especially in early adolescence, are not permitted to make many autonomous decisions of real consequence (Moffitt, 1993). Adolescents are aware of the lack of corresponding social maturity afforded to them, creating this uncomfortable discrepancy. Adolescents trapped in this maturity gap may look to older (more delinquent) adolescents who appear to be more mature and to be afforded more autonomy for ways to cope with this discrepancy. In this regard, adolescent-limited delinquency is considered to be a way of "knifing off childhood apron strings" (Moffitt, 1993, p. 688), in which adolescents can demonstrate that they and their beliefs are distinct from those of their parents. Indeed, delinquency that is confined to the adolescent years is expected to be less pathological and more age normative (Barnes \& Beaver, 2010). However, whereas delinquency may be a prevalent response to the changing biological and social circumstances of adolescence it is not without consequences. Certainly, adolescents may find themselves ensnared in a deviant lifestyle due to the potentially damaging consequences of this delinquency (e.g., the snare hypothesis; Moffitt, 1993).

In contrast to the developmental taxonomy (Moffitt, 1993), in his social control theory, Hirschi (1969) considers delinquency to be normative, but preventable. This theory suggests that adolescents with weakened bonds or commitments to parents, teachers, or schools, for example, may perceive delinquency to be less costly in comparison with adolescents with strong bonds or commitments, who may feel as if they have something to lose by being delinquent. These social bonds can be comprised of different elements, though they are most commonly associated with attach- ment and commitment (e.g., Costello \& Vowell, 1999). Attachment is the emotional closeness that adolescents have with conventional people, for example, their parents or teachers; whereas commitment involves adolescents' commitment to long-term conventional goals, for example, their educational commitments (Lilly, Cullen, \& Ball, 2014). For some adolescents, delinquency may also be interpreted as an expression of an inability to have these positive bonds, or as a lack of conventional goals. While Hirschi's expectations outlined in his social control theory do not exclude the possibility that developmental changes naturally weaken the strength of these bonds, he does suggest that adolescents who, for example, maintain close bonds with their parents or strong commitments to school, and therefore maintain ties to conventional society, will be protected from delinquency, whereas those who do not will have a greater risk for delinquency. And while there are obvious differences between these two theories of adolescent delinquency, there is one underlying similarity which relates them to each other and also to identity formation as theorized by Erikson (1968). Namely, these theories assume that some minor delinquency in adolescence can be expected. Therefore, together these theories form the basis for adolescent delinquency theory to which we link adolescent identity theory.

\section{Adolescent Identity Theory}

During the adolescent period in which we see the increase, peak, and subsequent decrease in delinquency, young people are simultaneously faced with the developmental task of forming a coherent personal identity - a subjective feeling of self-sameness and continuity over time (Erikson, 1950, 1968). Indeed, Erikson (1968) suggested that adolescents may be stuck in a role vacuum or psychosocial moratorium in which their role is ambiguous for both themselves and adults. This role-vacuum period is an integral part of identity formation as it provides the necessary opportunity for adolescents to explore their own interests, views, and beliefs in order to make different identity commitments, distinct from those internalized during childhood. In doing so, adolescents can move between two opposing endpoints of identity formation: synthesis and confusion. Adolescents who make meaningful choices about their identity and form stable commitments can achieve a unique personal identity. Adolescents who move from one commitment to another and as a result, lack a sense of meaning or purpose, can remain in a state of identity confusion (Erikson, 1950).

Erikson's ideas on the identity formation process inspired many different conceptualizations of identity. For instance, the notion of identity synthesis and confusion stimulated the identity status model (Marcia, 1966), which, in turn, inspired the Meeus-Crocetti model (Crocetti, Rubini, \& Meeus, 2008; Meeus, van de Schoot, Keijsers, Schwartz, \& Branje, 2010) used in the current paper. In the Meeus-Crocetti model, commitment and in-depth exploration, on the one hand, and reconsideration of commitments, on the other hand, represent the two opposing dimensions of identity formation (i.e., synthesis vs. confusion). Specifically, commitment refers to firm choices that adolescents make with regards to various developmental domains, and the self-confidence that is derived from these choices; in-depth exploration refers to the extent to which adolescents actively explore their commitments, gather new information about these commitments, and discuss their commitments with others; and reconsideration of commitment refers to the 
comparison of current commitments to possible alternatives, and adolescent's efforts to change their current commitments when they are no longer appropriate or satisfactory (Crocetti, Sica, Schwartz, Serafini, \& Meeus, 2013). Although reconsideration may be important for finding more satisfying commitments (for instance, in the case of reconsidering friendships and educational commitments during the transition from middle school to high school), when it occurs it leads to a temporary crisis, related to the loss of current routines and certainties. The interplay between these three processes underlines a dual-cycle process (Luyckx, Goossens, \& Soenens, 2006; Meeus, 2011). In the first cycle, adolescents form commitments by considering and reconsidering them (identity formation). In the second cycle, adolescents explore their current commitments in depth, which aides in the consolidation of commitments (identity maintenance). Therefore, by including commitment, in-depth exploration, and reconsideration, this model aims to capture the dynamic process behind Erikson's (1968) identity synthesis versus identity confusion.

\section{Integrating Delinquency and Identity Theories}

By linking delinquency and identity theories we can conceptualize different possibilities for the expected developmental order of these two adolescent phenomena. First, we consider that exploration by means of delinquency may not only be a response to the maturity gap or psychosocial role vacuum, but in the same manner may also be explicitly related to the process of identity development. For instance, rebellious, deviant, and otherwise delinquent behavior may all be used as a means for identity exploration (Erikson, 1962; Erikson \& Erikson, 1957) suggesting that in the process of searching for independence, autonomy, and their own identity, adolescents might also (misguidedly) experiment with deviancy.

However, it is important to note that even if delinquency is a means of exploring identity alternatives, it can still have negative consequences on identity formation and the successful transition into adulthood. For instance, engaging in delinquency may also be related to identity confusion indirectly via ensnaring consequences such as poor school attachment (Agnew, 1991; Hoffmann, Erickson, \& Spence, 2013), poor academic achievement or school dropout (e.g., Moffitt et al., 2002; Siennick \& Staff, 2008), poor relationships with parents (e.g., Warr, 2007), or poor relationships with peers that could, in turn, hamper identity synthesis. For example, decreased academic achievement can damage adolescents' commitment to school (e.g., Pop, Negru-Subtirica, Crocetti, Opre, \& Meeus, 2016), and strained relations with nondelinquent friends may lead to reconsideration of close friendships. Therefore, we expect that adolescent delinquency may hamper identity synthesis and promote identity confusion.

Second, in the social control theory Hirschi (1969) hypothesizes that weak or absent social bonds (e.g., commitments) will lead to delinquency. This weakening or absence of commitments to conventional society corresponds with Erikson's expectations that adolescents who struggle to find meaningful conventional commitments will experience difficulties in successfully forming their own identity. Therefore, we consider that adolescents who are unable to commit to conventional life goals may fail to experience the turning points in identity development and therefore may be unable to make the firm commitments necessary for identity synthesis.

However, a lack of strong bonds or commitments to conventional society, as well as the inability to make these firm commitments may also reflect interindividual differences that affect personal capabilities (e.g., impulsivity, lack of future goals or planfulness, decision-making, and judgment abilities) related to successful identity formation. Indeed, young people who cannot vividly envision their future self are more likely to make delinquent choices (van Gelder, Hershfield, \& Nordgren, 2013). And it has also been suggested that adolescents who do not understand how their behavior is related to the attainment of goals are more likely to be delinquent (Hirschi, 1969). Therefore, it is important to note that there is individual variation in personal capabilities and characteristics related to successful identity formation. Certainly, identity formation seems to come much more easily for some adolescents than for others (Erikson \& Erikson, 1957). Strong bonds to parents or other conventional institutions may protect adolescents from delinquency by positioning them into conformity. Further, and again related to the developmental taxonomy, they may also be indicators of the ability to form identity commitments more easily, without the need for much exploration, and therefore limit opportunities to misstep into delinquency (e.g., Benson, Harris, \& Rogers, 1992; Meeus, Oosterwegel, \& Vollebergh, 2002). Therefore, we consider successful personal identity formation and the corresponding ability to make firm identity commitments (e.g., to education or friends) to be an indicator of both good bonds (e.g., social control theory) as well as social maturity (e.g., developmental taxonomy), both of which aid adolescents in avoiding delinquency. Therefore, we also expect that identity synthesis may protect against delinquency while identity confusion may promote delinquency.

\section{The Empirical Relation Between Delinquency and Identity}

While experimenting with delinquency and personal identity formation processes may be conceptually related, this link has rarely been examined longitudinally or within persons. Nevertheless, recent between-person cross-sectional research found that externalizing problems and identity were indeed related during adolescence: Adolescents in a juvenile penitentiary reported less commitment, less in-depth exploration, and more reconsideration in comparison with a group of adolescents from the general community (Klimstra et al., 2011). Higher reconsideration was also related to more self-reported delinquency in Dutch adolescents (Crocetti et al., 2008) and higher parent-reported externalizing problems in Japanese adolescents (Hatano, Sugimura, \& Crocetti, 2016).

In one of the few longitudinal studies to date, externalizing problems in early adolescence were related to higher levels of reconsideration in middle-to-late adolescence (Crocetti, Klimstra, Hale, Koot, \& Meeus, 2013). Finally, when identity dimensions (commitment, in-depth exploration, and reconsideration) were combined into identity statuses, adolescents in statuses characterized by low commitment reported more delinquency across four years of adolescence than adolescents in statuses characterized by high commitment (Meeus, van de Schoot, Keijsers, \& Branje, 2012). Overall, based on current empirical evidence we can con- 
clude that delinquency and externalizing problems have been negatively related to indicators of identity synthesis and positively related to indicators of identity confusion (see also: Schwartz et al., 2009).

\section{Examining Both Between- and Within-Person Associations}

In this study, we aimed to examine the longitudinal associations between delinquency and identity across adolescence. Examining both between- and within-person approaches can further increase our understanding of the relation between delinquency and identity as these two approaches capture distinct developmental processes. On the one hand, between-person models provide information about the rank-order stability within a group over time (Papp, 2004). More specifically, using delinquency and reconsideration as an example, a between-person model could inform us as to whether adolescents who score higher on reconsideration relative to their peers also score higher on delinquency relative to their peers one year later. Therefore, in between-person models it is necessary to consider the adolescents' scores in relation to the average score of all adolescents (i.e., rank-order stability). On the other hand, within-person models provide evidence of the dynamic relation between two variables within one person (Papp, 2004). Therefore, using delinquency and reconsideration as an example, a within-person model could potentially inform as to whether an increase in an adolescent's own score on reconsideration would lead to an increase in the same adolescent's delinquency. Therefore, in within-person models it is necessary to consider adolescents' scores in relation to their own average score (i.e., akin to causal processes).

While previous research has primarily focused on empirically testing between-person differences in the relation between delinquency and identity (e.g., adolescents with weaker bonds than their peers may be more delinquent than peers with stronger bonds) delinquency and identity theory also refer to processes occurring within-persons (e.g., adolescents who report a decrease in their own bonds may subsequently be more likely to be delinquent than when they reported stronger bonds). Therefore, to better understand how the theoretically hypothesized between-person differences and within-person changes in delinquency and identity are related across adolescence we addressed both between- and within-person processes in this study.

\section{The Present Study}

Building upon the delinquency (i.e., Hirschi, 1969; Moffitt, 1993) and identity (i.e., Crocetti et al., 2008; Erikson, 1950) theories linked above, this study aimed to examine the longitudinal associations between delinquency and identity. We proposed the following between-person hypotheses based on this theoretical link: (a) increased delinquency (relative to peers) may hamper identity synthesis and promote identity confusion (relative to peers), and (b) increased identity synthesis (relative to peers) may protect against delinquency while identity confusion may promote delinquency (relative to peers). We also proposed the following within-person hypotheses based on this theoretical link: (c) increased delinquency (compared with adolescents' own average) may hamper identity synthesis and promote identity confusion (compared with adolescents' own average), and (d) increased identity synthesis (compared with adolescents' own average) may protect against delinquency while identity confusion may promote delinquency (compared with adolescents' own average).

\section{Method}

\section{Participants}

This study used data from the Research on Adolescent Development and Relationships-Young Cohort (RADAR-Young) project, a prospective multimethod, multi-informant, longitudinal cohort study on adolescent development. In the current study, we used five waves of data from the RADAR-Young sample, which consists of 497 Dutch families: mother, father, and target adolescent $\left(57 \%\right.$ boys; baseline $\left.M_{\text {age }}=14.03, S D=0.46\right) .{ }^{1}$ Target adolescents were recruited from 230 schools that were randomly selected from a list of regular primary education schools in the western and central region of the Netherlands. During data collection, participating adolescents were attending secondary school, most of them (85\%) lived with both biological parents, were classified as having a medium-to-high socioeconomic status (89\%), and reported their ethnicity as Dutch-Caucasian (97\%).

At the last measurement wave (when adolescents were 18 years old), 425 families (90\%) were still participating in the study. We used Little's (1988) missing completely at random test to examine our missing data. Based on the acceptable $\chi^{2} / d f=1.17$ ratio (e.g., Bollen, 1989), we included participants with partially missing data in our analyses and estimated missing data using full information maximum likelihood available in Mplus Version 7.3 (Muthén \& Muthén, 1998-2015).

\section{Procedure}

Written information was sent to families' homes, and both adolescents and parents provided written informed consent before study participation. Annual assessments were conducted in the target adolescent family homes by trained researchers. Researchers ensured that the battery of paper questionnaires were completely individually and confidentially. The Utrecht University Medical Ethical Board approved this study.

\section{Measures}

Delinquency. Adolescents' delinquency was rated by three informants: adolescent themselves, their mothers, and their fathers. More specifically, at each measurement wave, adolescents reported on their own delinquency in the past 6 months, using the Dutch version (Verhulst, van der Ende, \& Koot, 1997) of the 11-item Youth Self Report (YSR) Delinquency subscale (Achenbach, 1991). Sample items include "I start fires" and "I steal from places other than home." YSR items were rated on a 3-point Likert scale, ranging from 0 (not true) to 2 (very true) and then summed to create a total scale.

\footnotetext{
${ }^{1}$ Although data collection for RADAR-Young began at age 13 (2006), identity measures were not included in the study until the second annual assessment at age 14 .
} 
Mothers and fathers reported on adolescents' delinquency in the past 6 months, using the Dutch version (Verhulst, van der Ende, \& Koot, 1996) of the 13-item Child Behavior Checklist (CBCL) Delinquency subscale (Achenbach, 1991). Sample items include "My child starts fires" and "My child steals from places other than home." The CBCL items were rated on a 3-point Likert scale, ranging from 0 (not true of my child) to 2 (very true of my child) and then summed for a total score.

Reliabilities at each wave ranged from .70 to .77 for adolescent reports, .70 to .80 for mother reports, and .69 to .78 for father reports. Further, the within-time-point correlations of these three informant scales ranged from .33 to $.52, p s<.001$ between mother and adolescent, .28 to $.41, p \mathrm{~s}<.001$ between father and adolescent and .50 to $.68, p s<.001$ between mother and father. Therefore, we created a composite multi-informant delinquency score based on the average of the summed total scales for adolescent, mother, and father reports of adolescent delinquency at each of the five annual waves.

Identity. Adolescents reported on their own identity processes using the Dutch version of the Utrecht-Management of Identity Commitments Scale (U-MICS; Crocetti et al., 2008). The U-MICS consists of 26 items with a response scale ranging from 1 (completely untrue) to 5 (completely true). Thirteen items refer to identity in the educational domain and the other 13 items refer to identity in the interpersonal domain. Sample items include: "My education/best friend gives me certainty in life" (commitment; 10 items), "I think a lot about my education/best friend" (in-depth exploration; 10 items), and "I often think it would be better to try to find a different education/best friend" (reconsideration of commitment; 6 items). Although the U-MICS assesses identity in different domains, these two domains can also be combined to measure overall identity. Previous research demonstrated the internal validity of the three-dimensional model across domains in different gender, age, and ethnic groups and countries using confirmatory factor analyses (e.g., Crocetti et al., 2008; Crocetti et al., 2015; Morsunbul, Crocetti, Cok, \& Meeus, 2014). In this study, Cronbach's alphas across waves ranged between .89 and .90 for commitment, .84 and .85 for in-depth exploration, and .80 and .84 for reconsideration of commitment.

\section{Results}

\section{Preliminary Results}

We conducted preliminary analyses in SPSS Version 22 (IBM Corp., Armonk, NY). Within-time correlations for delinquency and each of the three identity constructs are reported in Table 1.
Notably, delinquency was negatively and significantly related to commitment. Delinquency was not significantly related to in-depth exploration and was positively and significantly related to reconsideration of commitment. Additionally, commitment and reconsideration are negatively correlated, whereas commitment and in-depth exploration are positively correlated. In-depth exploration and reconsideration are not significantly related to each other within time.

The means, standard deviations, medians, and interquartile ranges for all study variables are reported in Table 2 . While the plausible maximum score on delinquency was 24.7 , the actual maximum observed at any given time point was 14.7 . Indeed, the mean scores for multi-informant delinquency are rather low $(M$ range $=2.22$ to $2.64 ; S D$ range $=2.04$ to 2.23 ). However, in each wave no fewer than $94 \%$ of adolescents reported to have committed at least one delinquent act according to at least one of the three informants.

\section{Cross-Lagged Analyses}

The main aim of this study was to examine whether there is a longitudinal association between delinquency and identity processes across adolescence, and if so, to examine whether the association between them was driven by delinquency, by identity, or bidirectionally. Further, because little is known about these developmental processes we examined how delinquency and identity are related over time, both between and within persons. We conducted two different types of cross-lagged panel models (CLPMs) between delinquency and identity processes (commitment, in-depth exploration, and reconsideration of commitment): first, standard CLPMs to address between-person associations and second, random-intercept CLPMs to address within-person associations (Hamaker, Kuiper, \& Grasman, 2015). All cross-lagged analyses were conducted in Mplus 7.3 (Muthén \& Muthén, 1998 2015). We used the maximum likelihood robust estimator to account for any nonnormality in the variables (Satorra \& Bentler, 2001).

In each model we tested for the cross-lagged paths from delinquency to identity and identity to delinquency while controlling for 1 -year stability paths (e.g., delinquency at age 14 predicting delinquency at age 15) and within-time correlations among all variables. We evaluated model fit using the comparative fit index (CFI), with values above .95 indicating excellent fit, and the root-mean-square error of approximation (RMSEA), with values below .08 suggesting an acceptable fit and values below .05 suggesting a good fit (Byrne, 2012). Further, in order to enhance model parsimony, we tested models where cross paths from de-

Table 1

Within-Time Correlation Ranges Between Study Variables at All Five Study Waves

\begin{tabular}{|c|c|c|c|}
\hline Measure & $\begin{array}{c}\text { Commitment } \\
\text { T1/T2/T3/T4/T5 }\end{array}$ & $\begin{array}{l}\text { In-depth exploration } \\
\text { T1/T2/T3/T4/T5 }\end{array}$ & $\begin{array}{l}\text { Reconsideration } \\
\text { T1/T2/T3/T4/T5 }\end{array}$ \\
\hline \multicolumn{4}{|l|}{ Commitment } \\
\hline Exploration & $.54^{* * * *} / .55^{* * * *} / .46^{* * * * *} / .46^{* * * *} / .55^{* * * *}$ & & \\
\hline Reconsideration & $-.29^{* * * *} /-.25^{* * * *} /-.35^{* * * *} /-.42^{* * * *} /-.41^{* * * *}$ & $.03 / .03 / .03 /-.01 /-.06$ & \\
\hline Delinquency & $-.17^{* * * *} /-.13^{* * *} /-.14^{* * *} /-.15^{* * *} /-.19^{* * * *}$ & $.01 / .02 / .02 /-.06 / .02$ & $.23^{* * *} / .18^{* * * *} / .30^{* * * *} .28^{* * * *} / .22^{* * * *}$ \\
\hline
\end{tabular}


Table 2

Means, Standard Deviations, Medians, Interquartile Ranges for Delinquency and Identity Processes Across Adolescence

\begin{tabular}{cccccc}
\hline & \multicolumn{5}{c}{ Age } \\
\cline { 2 - 6 } & Age 14 & Age 15 & Age 16 & Age 17 & Age 18 \\
Measure & $M(S D)$ & $M(S D)$ & $M(S D)$ & $M(S D)$ & $M(S D)$ \\
& $M d n(\mathrm{IQR})$ & $M d n(\mathrm{IQR})$ & $M d n(\mathrm{IQR})$ & $M d n(\mathrm{IQR})$ & $M d n(\mathrm{IQR})$ \\
\hline \multirow{2}{*}{ Delinquency } & $2.22(2.10)$ & $2.38(2.14)$ & $2.67(2.23)$ & $2.68(2.23)$ & $2.64(2.04)$ \\
& $1.67(2.00)$ & $1.67(2.67)$ & $2.00(2.67)$ & $2.00(2.67)$ & $2.00(2.33)$ \\
Commitment & $3.68(.62)$ & $3.62(.65)$ & $3.61(.64)$ & $3.62(.68)$ & $3.59(.70)$ \\
& $3.80(.70)$ & $3.70(.80)$ & $3.70(.80)$ & $3.70(.80)$ & $3.70(.80)$ \\
Exploration & $3.25(.63)$ & $3.25(.63)$ & $3.19(.65)$ & $3.22(.64)$ & $3.22(.64)$ \\
& $3.20(.70)$ & $3.20(.80)$ & $3.20(.80)$ & $3.20(.70)$ & $3.20(.80)$ \\
Reconsideration & $1.86(.76)$ & $1.82(.71)$ & $1.89(.75)$ & $1.90(.78)$ & $1.97(.75)$ \\
& $1.83(1.17)$ & $1.67(.83)$ & $1.83(1.00)$ & $1.83(1.00)$ & $2.00(1.00)$ \\
\hline
\end{tabular}

Note. $\quad \mathrm{IQR}=$ interquartile range. Delinquency was scored on scale from 0 to 24.7 , and identity processes on a scale from 1 to 5 .

linquency to identity, and identity to delinquency (M2), and T2-T5 within-time correlations (M3) were constrained to be time invariant. Finally, we tested a model with all cross paths and T2-T5 within-time correlations constrained to be time invariant (M2 + M3 = M4). These models were compared with the unconstrained baseline model (M1). In order to determine significant differences between models at least two out of these three criteria had to be met: $\Delta \chi_{\mathrm{SB}}^{2}$ is significant at $p<.05$ (Satorra \& Bentler, 2001); $\Delta \mathrm{CFI} \geq-.010 ; \Delta$ RMSEA $\geq .015$ (Chen, 2007). Table 3 presents the fit and model comparison results for each of our models. In all cases, the constrained models fit the data well. Therefore, we reported the most parsimonious models (M4) as our final models. ${ }^{2}$

Between-Person Cross-Lagged Analyses. Using the betweenperson CLPMs, we were able to assess the extent to which scoring relatively high or low on identity at age 14 compared with peers predicted scoring relatively high or low on delinquency at age 15 , after controlling for prior delinquency at age 14. Cross-lagged paths presented in Figure 1 show that delinquency predicted decreased commitment and increased reconsideration of commitment, but was unrelated to in-depth exploration over time. The cross paths from the three identity constructs to delinquency were nonsignificant.

Table 4 presents the one-wave stability paths. Regarding withintime model associations, at age 14 delinquency was negatively correlated with commitment, $r=-.17, p<.001$, not significantly related to in-depth exploration, $r=.00, p>.05$, and positively correlated with reconsideration, $r=.23, p<.001$. At ages 15 to 18 (e.g., correlated changes), only delinquency and reconsideration continued to be significantly and positively related, $r=.11, p<$ .001 .

Within-Person Cross-Lagged Analyses. Using random intercepts CLPMs (RI-CLPMs; see Hamaker et al., 2015 for a detailed overview), we included random intercepts for each construct (i.e., a factor with all loadings constrained to 1) to partial out stable between-person variance, so that the cross-lagged paths only refer to within-person dynamics. With regard to the betweenperson variance portion of this model, Figure 2 shows that the time-invariant individual differences (i.e., the random intercepts) for delinquency and reconsideration were positively correlated, as were those between commitment and exploration. Reconsideration and commitment were negatively correlated.
Because between-person variance has been partialed out by the inclusion of the random intercept the rest of the model refers to within-person development. The cross-lagged paths presented in Figure 2 show that when an adolescent had a higher level of delinquency in the prior year than they usually have, they reported increased reconsideration (i.e., greater identity confusion) and decreased commitment in the following year. Therefore, these associations between delinquency, reconsideration, and commitment are similar in the between- and within-person models. However, in the RI-CLPM we also found cross-lagged effects from identity to delinquency: increased exploration predicted decreased delinquency one year later.

One-wave stability paths are reported in Table 4. Regarding the within-time model associations, at age 14, delinquency was negatively correlated with commitment, $r=-.17, p<.05$, not significantly related to in-depth exploration $(r=-.15 p=.08)$, and positively correlated with reconsideration, $r=.17, p<.05$. Only delinquency and reconsideration continued to be significantly related from ages 15 to $18, r=.13, p<.01$.

\section{Discussion}

In this study we aimed to provide a global overview of how between-person differences and within-person changes in delinquency and identity are related across adolescence. We conducted between- and within-person CLPMs in a five-wave sample of 497 adolescents to examine theoretically integrated hypotheses: increased delinquency (i.e., relative to peers or relative to adolescents' own average) may hamper identity synthesis and promote identity confusion (i.e., relative to peers or relative to adolescents' own average); and increased identity synthesis (i.e., relative to peers or relative to adolescents' own average) may protect against delinquency while identity confusion may promote delinquency (i.e., relative to peers or relative to adolescents' own average).

\footnotetext{
${ }^{2}$ The between-person cross-lagged panel models were also tested including gender and parents' occupation level (socioeconomic status [SES]) as covariates. Delinquency and the three identity constructs were regressed on gender and SES at each time point, therefore removing all shared variance between covariates, delinquency, and identity. The results from these models were very similar to the more parsimonious models presented here.
} 
Table 3

Fit Indices and Model Comparisons for Between- and Within-Person Cross-Lagged Panel Models

\begin{tabular}{|c|c|c|c|c|c|c|c|c|c|c|}
\hline \multirow[b]{2}{*}{ Model } & \multicolumn{4}{|c|}{ Model fit indices } & \multirow[b]{2}{*}{ Models } & \multicolumn{5}{|c|}{ Model comparisons } \\
\hline & $\chi_{S \mathrm{SB}}^{2}$ & $d f$ & CFI & RMSEA [90\% CI] & & $\Delta \chi_{\mathrm{SB}}^{2}$ & $d f$ & $p$ & $\Delta \mathrm{CFI}$ & $\Delta$ RMSEA \\
\hline \multicolumn{11}{|l|}{ Between-person CLPM } \\
\hline M1: baseline & 281.63 & 120 & .943 & $.053[.045, .061]$ & & & & & & \\
\hline M2: time invariant cross lags & 303.91 & 138 & .942 & $.050[.042, .057]$ & M2-M1 & 26.86 & 18 & .08 & -.001 & -.003 \\
\hline M3: T2-T5 time invariant within-time correlations & 290.52 & 138 & .946 & $.048[.040, .055]$ & M3-M1 & 15.90 & 18 & .81 & .003 & -.005 \\
\hline $\mathrm{M} 4: \mathrm{M} 2+\mathrm{M} 3$ & 312.46 & 156 & .945 & $.045[.038, .053]$ & M4-M1 & 31.54 & 36 & .62 & .002 & -.008 \\
\hline \multicolumn{11}{|l|}{ Within-person CLPM } \\
\hline M1: baseline & 100.11 & 110 & 1.00 & $.000[.000, .018]$ & & & & & & \\
\hline M2: time invariant cross lags & 125.24 & 128 & 1.00 & $.000[.000, .021]$ & M2-M1 & 25.53 & 18 & .11 & .000 & .000 \\
\hline M3: T2-T5 time invariant within-time correlations & 118.08 & 128 & 1.00 & $.000[.000, .017]$ & M3-M1 & 17.74 & 18 & .47 & .000 & .000 \\
\hline M4: M2 + M3 & 141.07 & 146 & 1.00 & $.000[.000, .019]$ & M4-M1 & 40.51 & 36 & .28 & .000 & .000 \\
\hline
\end{tabular}

Note. $\quad$ CLPM = cross-lagged panel model; $\chi^{2}=$ chi-square; $d f=$ degrees of freedom; CFI = comparative fit index; RMSEA = root-mean-square error of approximation; $\mathrm{CI}=$ confidence interval; $\Delta=$ change in parameter. $\Delta \chi_{\mathrm{SB}}^{2}$ model comparisons are based on Satorra and Bentler's (2001) scaled difference chi-square test statistic.

Our findings show that adolescents who are more delinquent than other adolescents are more likely to report increased identity confusion in comparison with the less delinquent adolescents. However, our findings also indicate that adolescents who show an increase in their own delinquent behavior are also more likely to report increased identity confusion than when their delinquency had remained stable. Relatedly, we also found some support for the hypothesis that identity synthesis protects against delinquency as increased in-depth exploration predicted a decrease in adolescents' own delinquency one year later. Overall, our results suggest that delinquency promotes identity confusion in adolescence. And while the most delinquent adolescents are certainly in need of attention, our results indicate that withinadolescent increases in delinquency also warrant attention. Finally, promoting within-adolescent increases in in-depth exploration may help prevent future adolescent delinquency.

\section{Delinquency Promotes Identity Confusion}

We had expected that delinquency could lead to identity confusion if adolescents who are in the process of differentiating

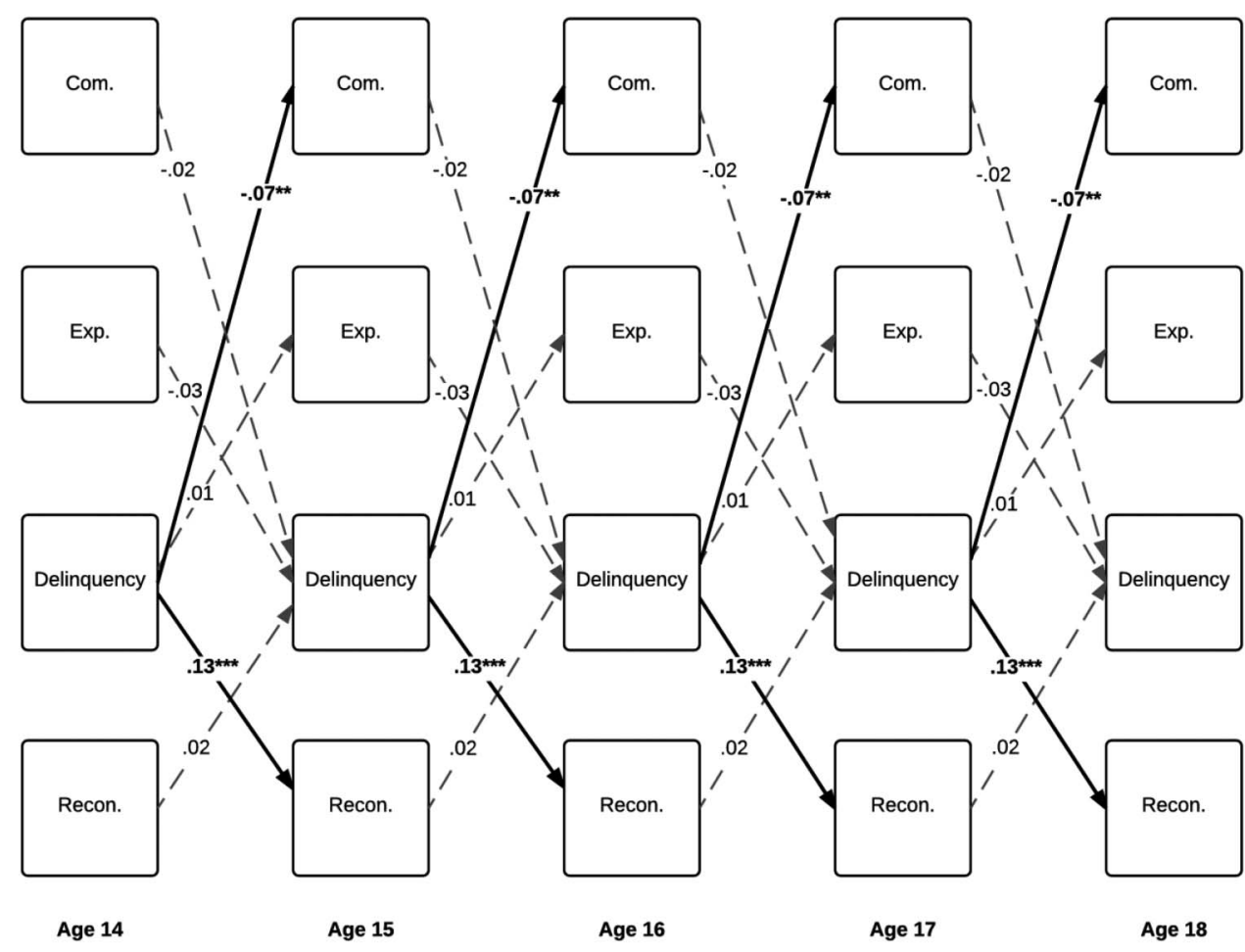

Figure 1. Standardized cross paths between delinquency and identity constructs for the final between-person cross-lagged panel model (M4). This model includes time-invariant cross lags, time-invariant T2-T5 within-time correlations, and one-wave stability paths. ${ }^{*} p<.05 .{ }^{* *} p<.01 .^{* * * *} p<.001$. 
Table 4

Standardized Autoregressive Coefficients for One-Wave Stability in Final Models

\begin{tabular}{lllll}
\hline & \multicolumn{4}{c}{ One-wave stability paths } \\
\cline { 2 - 5 } Measure & Age 14-15 & Age 15-16 & Age 16-17 & Age 17-18 \\
\hline Between-person & & & & \\
CLPM & & & & \\
Delinquency & $.73^{* * *}$ & $.78^{* * * *}$ & $.76^{* * * *}$ & $.79^{* * * *}$ \\
Commitment & $.44^{* * * *}$ & $.51^{* * * *}$ & $.53^{* * * *}$ & $.53^{* * * *}$ \\
Exploration & $.45^{* * * *}$ & $.45^{* * *}$ & $.51^{* * * *}$ & $.57^{* * * *}$ \\
Reconsideration & $.34^{* * * *}$ & $.44^{* * *}$ & $.39^{* * * *}$ & $.43^{* * * *}$ \\
Within-person & & & & \\
CLPM & & & $.62^{* * * *}$ & $.64^{* * * *}$ \\
Delinquency & $.52^{* * *}$ & $.62^{* * *}$ & $.21^{* * * *}$ & $.24^{* * * *}$ \\
Commitment & .08 & $.20^{* * *}$ & $.22^{* * * *}$ & $.26^{* * * *}$ \\
Exploration & .10 & .11 & $.21^{* * *}$ & $.27^{* * * *}$ \\
Reconsideration & $.18^{* *}$ & $.30^{* * *}$ & & \\
\hline
\end{tabular}

Note. $\quad$ CLPM $=$ cross-lagged panel model.

${ }^{*} p<.05 .{ }^{* *} p<.01 .^{* * *} p<.001$.

themselves from their childhood identifications used delinquency to exert autonomy, independence, and explore possible identity alternatives. Our findings provided strong support for our hypothesis that delinquency may hamper identity synthesis and promote identity confusion. Specifically, the between-person analysis indicated that, on average, adolescents who scored higher than their peers on delinquency also scored higher than their peers on reconsideration, and lower on commitment 1 year later. The withinperson analysis indicated that adolescents who report delinquency higher than their own average report more reconsideration and less commitment in comparison with their own average, 1 year later. These relations between delinquency, reconsideration and commitment are consistent with previous research that found a positive relation between delinquency and identity confusion (e.g., Schwartz, Pantin, Prado, Sullivan, \& Szapocznik, 2005; Schwartz, Mason, Pantin, \& Szapocznik, 2008) and delinquency and reconsideration (e.g., Crocetti et al., 2008; Crocetti, Klimstra, et al., 2013; Klimstra et al., 2011) and a negative relation between delinquency and commitment (Klimstra et al., 2011; Meeus et al., 2012). Our results further build on these studies by providing longitudinal evidence of a developmental order from delinquency to identity.

It is worth noting that delinquent behavior does not guarantee that an adolescent will be ensnared into a trajectory leading to identity confusion. Indeed, reconsideration of current commitments in comparison with potential alternatives can be desirable or adaptive when current commitments are not appropriate (Klimstra, Hale, Raaijmakers, Branje, \& Meeus, 2010). Therefore, we also suggest that adolescents who engage in delinquency are not only at risk of being ensnared into identity confusion because they are unsure of their commitments or labeled into a delinquent identity, but also because they may be missing conventional goals to which they could reorientate or commit. Indeed, this absence of suitable alternatives could also be one of the ensnaring consequences of delinquency (e.g., Moffitt et al., 2002; Siennick \& Staff, 2008; Warr, 2007) such as school failure or damaged relationships that may decrease both commitment-making as well as adolescents' possibilities for conventional alternatives or goals.
While delinquency may be related to identity confusion by decreasing the number of conventional alternatives to which adolescents can commit either by means of labeling or other ensnaring consequences of delinquency such as school failure and damaged relationships, we propose that our findings could also be explained by other mechanisms. For example, delinquent adolescents may be less capable of forming the stable commitments associated with identity formation. This idea is supported by previous research on identity styles. For instance, identity styles research proposes three different ways (informational, normative, and diffuse-avoidance styles) in which adolescents can approach identity-relevant tasks (Berzonsky, 1990).

Adolescents who engage in the diffuse-avoidance identity style are typically thought to avoid dealing with their identity issues, instead defining themselves in terms of social attributes such as reputation and popularity (Berzonsky, Macek, \& Nurmi, 2003). Further, the diffuse-avoidance identity style has been associated with both lower commitment and higher reconsideration (Crocetti, Rubini, Berzonsky, \& Meeus, 2009) as well as increased externalizing problems (Adams, Munro, Munro, Doherty-Poirer, \& Edwards, 2005). These adolescents also tend to lack self-awareness and display high levels of self-handicapping, impulsivity, and behave in accordance with situation-specific demands in contrast to planned behaviors (Berzonsky \& Ferrari, 2009). This explanation is further consistent with the finding that delinquent adolescents do not make concrete investments in their educational goals, and in the meanwhile tend to overestimate their own academic achievements (Siennick \& Staff, 2008). Naturally, this combination of a lack of investment in and an overevaluation of results is related to a decreased likelihood of successful goal attainment. Therefore, while it is possible that adolescents do not understand the consequences of their own delinquency, it seems even more likely that delinquent adolescents lack the skills and selfawareness to adequately position themselves in society in order to achieve concrete goals and make firm identity commitments. Future research should test these two alternative explanations for the finding that between-person differences and within-person changes in delinquency promote identity confusion.

\section{Identity Synthesis Protects Against Delinquency}

Our second theoretically based hypothesis was that identity synthesis might protect adolescents from engaging in delinquency. Adolescents who have good bonds (either attachments or commitments) with parents, teachers, and societal institutions are less likely to be delinquent and adolescents with these ties to society are hypothesized to better understand the consequences of potential delinquency on their goals (Hirschi, 1969; Hoeve et al., 2012). In fact, already having strong bonds may even represent an ability to make firm identity commitments more easily as attachment and identity commitment have been positively related (Meeus et al., 2002). Our results provided modest evidence in support of this hypothesis within persons: more in-depth exploration (i.e., one aspect of identity synthesis) predicted adolescents' own decreased delinquency 1 year later.

Based on this finding we suggest that an active effort to move toward identity synthesis by engaging in in-depth exploration may protect adolescents from delinquency. These adolescents may avoid delinquency in order to avoid jeopardizing the potential to 


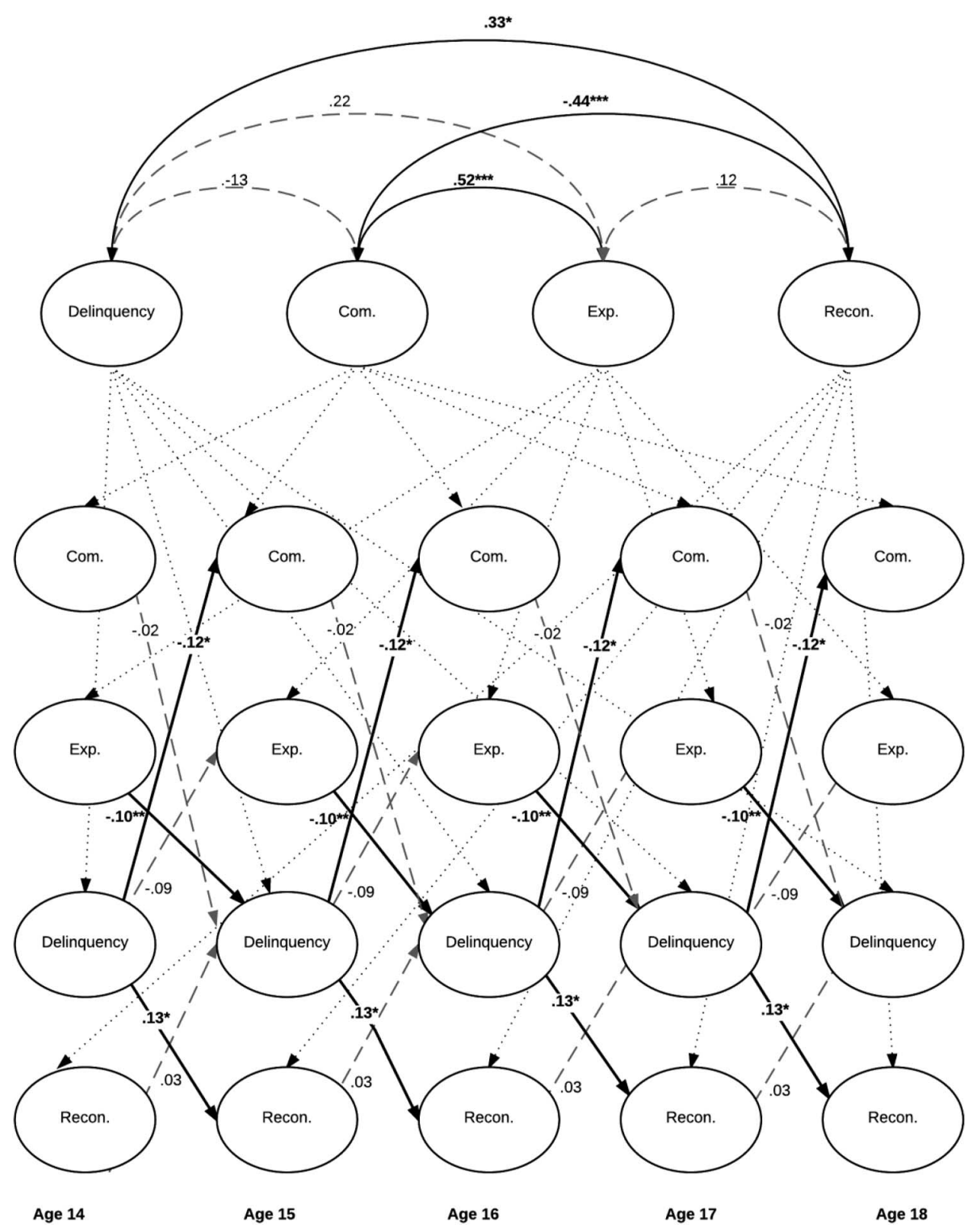

Figure 2. Correlations between time-invariant between-person latent variables (upper figure) and standardized cross-paths (lower figure) for delinquency and identity constructs for the final within-person cross-lagged panel model (M4). This model includes time-invariant cross lags, time-invariant T2-T5 within-time correlations, and one-wave stability paths. ${ }^{*} p<.05 .{ }^{* *} p<.01 .{ }^{* * * *} p<.001$.

form goals or make firm commitments in the near future. This explanation is also supported by previous research on identity styles (i.e., Berzonsky, 1990). For instance, the informational style is generally related to high self-reflection, high self-regulation, being effortful and deliberate in pursuit of an own identity, and actively working to meet their own personal standards and goals (Berzonsky, Cieciuch, Duriez, \& Soenens, 2011; Berzonsky \& Ferrari, 2009; Soenens, Berzonsky, Vansteenkiste, Beyers, \& Goossens, 2005). Further, the informational style has been strongly related to higher levels of in-depth exploration in adolescence (Crocetti et al., 2009). In this regard, encouraging adolescents to increase their own in-depth exploration, resulting in withinadolescent changes, may provide a manageable short-term goal which, in turn, increases their own engagement in identity formation and decreasing willingness or likelihood to misstep (e.g., delinquency) in their search for alternative possibilities.

\section{Delinquency, Identity Formation, and Peers}

The aim of this paper was to address a theoretical link between adolescent delinquency and adolescent identity formation that has, to date, not received much attention in the identity literature, while 
at the same time provide a more complete overview of the developmental interplay between delinquency and identity development by examining both between- and within-person associations. Our results indeed suggest that these two aspects of adolescence are related, and some of the broad mechanisms by which this may operate have been outlined related to our specific directional findings above. However, we do want to draw additional and explicit attention to the possibility of the role of friends and the peer context in explaining this relationship. Indeed, the types of minor adolescent delinquency displayed in this sample are most often conducted when adolescents are socializing in unsupervised groups, as delinquency in this context is both easier and more rewarding (Osgood, Wilson, O’Malley, Bachman, \& Johnston, 1996). Additionally, adolescents are known to be highly similar to their best friends in their level of delinquency (Mercer, Keijsers, Crocetti, Branje, \& Meeus, 2016) but also to be directly influenced by their peers' delinquent behavior (e.g., Gallupe et al., 2016; Paternoster, McGloin, Nguyen, \& Thomas, 2013).

Furthermore, with regard to identity development, the peer context is thought to be a social laboratory for adolescents to try out different roles and identities in the process of self-exploration while receiving feedback from their peer group (Sherif \& Sherif, 1964). Indeed, when friends narrate about their experiences they provide self-relevant feedback to each other on their identity choices (Kerpelman, Pittman, \& Lamke, 1997) which may be particularly important to understanding the mechanisms underlying the negative relation between in-depth exploration and delinquency. Furthermore, recent research has found that while friends' educational identity was unrelated to adolescents' own identity, adolescents' own educational identity was related to the level of balanced relatedness perceived in their relationship with their best friend (van Doeselaar, Meeus, Koot, \& Branje, 2016). Specifically, perceiving the best friendship to be high in balanced relatedness was related to decreased educational reconsideration over time, indicating that best friendships that were perceived as positive were related to decreased problems in educational identity formation.

Therefore, given the importance of the peer context and social relationships in both delinquency and identity formation, we suggest that future research expand on this initial theoretical link between delinquency and identity formation to include the possibility of the role of peers or friends in the link between delinquency and identity formation. Based on the research mentioned above, the amount of peer and best friend delinquency, time spent with peers in unstructured settings, or the (perceived) quality of best friendships could be plausible starting points to better understand potential moderators and/or mechanisms underlying this developmental relation.

\section{Strengths, Limitations, and Suggestions for Future Research}

This study was the first to test the longitudinal association between delinquency and identity formation both between- and within-persons using a multi-informant five-wave sample of adolescents. Nevertheless, we have four suggestions for ways in which future research could improve and extend upon this study. First, we encourage future research to examine if the longitudinal association between delinquency and identity is the same across dif- ferent subgroups of delinquent adolescents. For example, the developmental taxonomy (Moffitt, 1993) is a group-based theory in which the large majority of adolescents are hypothesized to engage in the adolescent-limited behavior described in this paper. However, this theory also includes a small group of life-coursepersistent delinquents for whom delinquency is hypothesized to have different antecedents, as well as a small group of adolescent delinquency abstainers who manage to avoid delinquency altogether. Future research could examine whether or not these processes are indeed the same across different groups of (non)delinquent adolescents (e.g., Mercer et al., 2016).

Second, this study was conducted in a sample of relatively homogeneous native-Dutch adolescents from a medium-to-high socioeconomic background, primarily living in two-parent households. Future studies should replicate these results in different groups of adolescents from different backgrounds or high-risk and clinical samples using different measures of delinquency and externalizing problems to determine if our results can be further generalized to adolescents (at risk for) showing greater levels of delinquent behavior. Indeed, the social context of the sample is important to consider as, for example, there is some evidence that adolescents who feel secure in their parental relationships are more likely to experiment with behavioral autonomy from their parents (Allen, Hauser, Bell, \& O'Connor, 1994) as well as to have higher levels of identity exploration (Quintana \& Lapsley, 1987) both of which may be related to high levels of experimenting with minor delinquency and rule-breaking (Brauer \& De Coster, 2015). Therefore, it is plausible that experimentation with minor delinquency is related to identity reconsideration in a "safer" environment, with a lower risk for negative consequences, for some adolescents. That being said, our results are consistent with the cross-sectional associations between delinquency and identity found in a personcentered study comparing high-risk youth currently in a juvenile penitentiary with a community sample of adolescents (e.g., Klimstra et al., 2011). Nevertheless, whether these longitudinal between and within-person associations would hold in a more seriously problematic sample of convicted delinquent youth, for example, is yet to be tested.

Third, since we know that prosocial and antisocial behavior are not necessarily opposite ends of the same continuum, the implications of these results for promoting prosocial behavior remain unknown. Although higher levels of prosocial behavior often coincide with lower levels of delinquent behavior, there is evidence that some young people exhibit a combination of both aggressive and prosocial behaviors in their peer relationships (McDonald, Benish-Weisman, O'Brien, \& Ungvary, 2015). Findings such as these are indicative of the value of looking at different identity constructs in relation to both prosocial and antisocial behaviors. Indeed, future research should consider how similar these relations would be with pro-social behavior in order to provide more knowledge of, for example, whether or not increasing in-depth exploration would decrease delinquency while also promoting prosocial behavior.

Finally, the main aim of this study was to test if the theoretical link between delinquency and identity could be empirically supported across adolescence and to determine what the developmental order of that link would be. Now that this first link has been established both between and within persons, future studies could aim to test the mechanisms underlying this developmental order. 
We have proposed some plausible mechanisms in the discussion of this paper, and undoubtedly there are many more to be considered as well. For example, given the importance of friends and peers for both delinquency and identity development, future research should certainly take adolescent social relationships into further consideration in unpacking this link. Further research is absolutely needed to understanding the mechanisms by which delinquency leads to increased identity confusion and how exactly in-depth exploration may prevent adolescent delinquency. Insight into these relations would be highly informative for making practical use of these findings in preventing delinquency.

\section{Conclusion}

Linking adolescent delinquency to the main developmental task of identity formation, we found that experimenting with delinquency hampers identity formation by increasing reconsideration and decreasing commitment between and within adolescents. Therefore, even if adolescent delinquency is more common and less pathological than delinquency at other ages it still impedes the main developmental task of identity formation. And while the most delinquent adolescents are certainly in need of attention, withinadolescent increases in delinquency also warrant attention. Certainly, future research should consider identity confusion as one of the potentially ensnaring consequences of adolescent delinquency. Additionally, within-persons increased in-depth exploration of identity commitments led to less delinquency over time. Therefore, interventions tailored to increase in-depth exploration in adolescents may aid in preventing adolescent delinquency.

\section{References}

Achenbach, T. M. (1991). Integrative guide for the 1991 CBCL/4-18, YSR, and TRF profiles. Burlington, VT: Department of Psychiatry, University of Vermont.

Adams, G. R., Munro, B., Munro, G., Doherty-Poirer, M., \& Edwards, J. (2005). Identity processing styles and Canadian adolescents' selfreported delinquency. Identity: An International Journal of Theory and Research, 5, 57-65. http://dx.doi.org/10.1207/s1532706xid0501_4

Agnew, R. (1991). The interactive effects of peer variables on delinquency. Criminology, 29, 47-72. http://dx.doi.org/10.1111/j.1745-9125.1991 .tb01058.x

Allen, J. P., Hauser, S. T., Bell, K. L., \& O’Connor, T. G. (1994). Longitudinal assessment of autonomy and relatedness in adolescentfamily interactions as predictors of adolescent ego development and self-esteem. Child Development, 65, 179-194. http://dx.doi.org/10 $.2307 / 1131374$

Barnes, J. C., \& Beaver, K. M. (2010). An empirical examination of adolescence-limited offending: A direct test of Moffitt's maturity gap thesis. Journal of Criminal Justice, 38, 1176-1185. http://dx.doi.org/10 $.1016 /$ j.jcrimjus.2010.09.006

Benson, M. J., Harris, P. B., \& Rogers, C. S. (1992). Identity consequences of attachment to mothers and fathers among late adolescents. Journal of Research on Adolescence, 2, 187-204. http://dx.doi.org/10.1207/ s15327795jra0203_1

Berzonsky, M. D. (1990). Self-construction over the life-span: A process perspective on identity formation. In G. J. Neimeyer \& R. A. Neimeyer (Eds.), Advances in personal construct theory (Vol. 1, pp. 155-186). Greenwich, CT: JAI Press.

Berzonsky, M. D., Cieciuch, J., Duriez, B., \& Soenens, B. (2011). The how and what of identity formation: Associations between identity styles and value orientations. Personality and Individual Differences, 50, 295-299. http://dx.doi.org/10.1016/j.paid.2010.10.007
Berzonsky, M. D., \& Ferrari, J. R. (2009). A diffuse-avoidant identity processing style: Strategic avoidance or self-confusion? Identity: An International Journal of Theory and Research, 9, 145-158. http://dx.doi .org/10.1080/15283480802683607

Berzonsky, M. D., Macek, P., \& Nurmi, J. E. (2003). Interrelationships among identity process, content, and structure: A cross-cultural investigation. Journal of Adolescent Research, 18, 112-130. http://dx.doi.org/ 10.1177/0743558402250344

Bollen, K. A. (1989). A new incremental fit index for general structural equation models. Sociological Methods \& Research, 17, 303-316. http:// dx.doi.org/10.1177/0049124189017003004

Brauer, J. R., \& De Coster, S. (2015). Social relationships and delinquency: Revisiting parent and peer influence during adolescence. Youth \& Society, 47, 374-394. http://dx.doi.org/10.1177/0044118X12467655

Byrne, B. M. (2012). Structural equation modeling with Mplus: Basic concepts, applications, and programming (2nd ed.). New York, NY: Routledge/Taylor \& Francis.

Chen, F. F. (2007). Sensitivity of goodness of fit indexes to lack of measurement invariance. Structural Equation Modeling, 14, 464-504. http://dx.doi.org/10.1080/10705510701301834

Chen, X. (2010). Desire for autonomy and adolescent delinquency: A latent growth curve analysis. Criminal Justice and Behavior, 37, 989-1004. http://dx.doi.org/10.1177/0093854810367481

Costello, B. J., \& Vowell, P. R. (1999). Testing control theory and differential association: A reanalysis of the Richmond Youth Project data. Criminology, 37, 815-842. http://dx.doi.org/10.1111/j.1745-9125 .1999.tb00506.x

Crocetti, E., Cieciuch, J., Gao, C. H., Klimstra, T., Lin, C. L., Matos, P. M., . . Meeus, W. (2015). National and gender measurement invariance of the Utrecht-Management of Identity Commitments Scale (U-MICS): A 10-nation study with university students. Assessment, 22, 753-768. http://dx.doi.org/10.1177/1073191115584969

Crocetti, E., Klimstra, T. A., Hale, W. W., III, Koot, H. M., \& Meeus, W. (2013). Impact of early adolescent externalizing problem behaviors on identity development in middle to late adolescence: A prospective 7-year longitudinal study. Journal of Youth and Adolescence, 42, 1745-1758. http://dx.doi.org/10.1007/s10964-013-9924-6

Crocetti, E., Rubini, M., Berzonsky, M. D., \& Meeus, W. (2009). Brief report: The identity style inventory-validation in Italian adolescents and college students. Journal of Adolescence, 32, 425-433. http://dx.doi .org/10.1016/j.adolescence.2008.04.002

Crocetti, E., Rubini, M., \& Meeus, W. (2008). Capturing the dynamics of identity formation in various ethnic groups: Development and validation of a three-dimensional model. Journal of Adolescence, 31, 207-222. http://dx.doi.org/10.1016/j.adolescence.2007.09.002

Crocetti, E., Sica, L. S., Schwartz, S. J., Serafini, T., \& Meeus, W. (2013). Identity styles, dimensions, statuses, and functions: Making connections among identity conceptualizations. European Review of Applied Psychology/Revue Européenne de Psychologie Appliquée, 63, 1-13. http:// dx.doi.org/10.1016/j.erap.2012.09.001

Erikson, E. H. (1950). Youth and society (p. 240). London, UK: Penguin Books.

Erikson, E. H. (1962). Youth, fidelity and diversity. Daedalus, 91, 5-27.

Erikson, E. H. (1968). Identity, youth, and crisis. New York, NY: Norton.

Erikson, E. H., \& Erikson, K. T. (1957). The confirmation of the delinquent. Chicago Review, 10, 15-23. http://dx.doi.org/10.2307/25293266

Farrington, D. P. (1986). Age and crime. Crime and Justice, 7, 189-250. http://dx.doi.org/10.1086/449114

Gallupe, O., Nguyen, H., Bouchard, M., Schulenberg, J. L., Chenier, A., \& Cook, K. D. (2016). An experimental test of deviant modeling. Journal of Research in Crime and Delinquency, 53, 482-505. http://dx.doi.org/ $10.1177 / 0022427815625093$ 
Hamaker, E. L., Kuiper, R. M., \& Grasman, R. P. (2015). A critique of the cross-lagged panel model. Psychological Methods, 20, 102-116. http:// dx.doi.org/10.1037/a0038889

Hatano, K., Sugimura, K., \& Crocetti, E. (2016). Looking at the dark and bright sides of identity formation: New insights from adolescents and emerging adults in Japan. Journal of Adolescence, 47, 156-168. http:// dx.doi.org/10.1016/j.adolescence.2015.09.008

Hirschi, T. (1969). Causes of delinquency. Berkeley, CA: University of California Press.

Hoeve, M., Stams, G. J. J., van der Put, C. E., Dubas, J. S., van der Laan, P. H., \& Gerris, J. R. (2012). A meta-analysis of attachment to parents and delinquency. Journal of Abnormal Child Psychology, 40, 771-785. http://dx.doi.org/10.1007/s10802-011-9608-1

Hoffmann, J. P., Erickson, L. D., \& Spence, K. R. (2013). Modeling the association between academic achievement and delinquency: An application of interactional theory. Criminology: An Interdisciplinary Journal, 51, 629-660. http://dx.doi.org/10.1111/1745-9125.12014

Kerpelman, J. L., Pittman, J. F., \& Lamke, L. K. (1997). Toward a microprocess perspective on adolescent identity development: An identity control theory approach. Journal of Adolescent Research, 12, 325346. http://dx.doi.org/10.1177/0743554897123002

Klimstra, T. A., Crocetti, E., Hale, W. W., Kolman, A. I., Fortanier, E., \& Meeus, W. H. (2011). Identity formation in juvenile delinquents and clinically referred youth. Revue European Review of Applied Psychology/Revue Européenne de Psychologie Appliquée, 61, 123-130. http:// dx.doi.org/10.1016/j.erap.2011.05.002

Klimstra, T. A., Hale, W. W., III, Raaijmakers, Q. A., Branje, S. J., \& Meeus, W. H. (2010). Identity formation in adolescence: Change or stability? Journal of Youth and Adolescence, 39, 150-162. http://dx.doi .org/10.1007/s10964-009-9401-4

Lilly, J. R., Cullen, F. T., \& Ball, R. A. (2014). Criminological theory: Context and consequences. London, UK: Sage.

Little, R. J. (1988). A test of missing completely at random for multivariate data with missing values. Journal of the American Statistical Association, 83, 1198-1202.

Luyckx, K., Goossens, L., \& Soenens, B. (2006). A developmental contextual perspective on identity construction in emerging adulthood: Change dynamics in commitment formation and commitment evaluation. Developmental Psychology, 42, 366-380. http://dx.doi.org/10 $.1037 / 0012-1649.42 .2 .366$

Marcia, J. E. (1966). Development and validation of ego-identity status. Journal of Personality and Social Psychology, 3, 551-558. http://dx.doi .org/10.1037/h0023281

McDonald, K. L., Benish-Weisman, M., O'Brien, C. T., \& Ungvary, S. (2015). The social values of aggressive-prosocial youth. Journal of Youth and Adolescence, 44, 2245-2256. http://dx.doi.org/10.1007/ s10964-014-0246-0

Meeus, W. (2011). The study of adolescent identity formation 2000-2010: A review of longitudinal research. Journal of Research on Adolescence, 21, 75-94. http://dx.doi.org/10.1111/j.1532-7795.2010.00716.x

Meeus, W., Oosterwegel, A., \& Vollebergh, W. (2002). Parental and peer attachment and identity development in adolescence. Journal of Adolescence, 25, 93-106. http://dx.doi.org/10.1006/jado.2001.0451

Meeus, W., van de Schoot, R., Keijsers, L., \& Branje, S. (2012). Identity statuses as developmental trajectories: A five-wave longitudinal study in early-to-middle and middle-to-late adolescents. Journal of Youth and Adolescence, 41, 1008-1021. http://dx.doi.org/10.1007/s10964-0119730-y

Meeus, W., van de Schoot, R., Keijsers, L., Schwartz, S. J., \& Branje, S. (2010). On the progression and stability of adolescent identity formation: A five-wave longitudinal study in early-to-middle and middle-to-late adolescence. Child Development, 81, 1565-1581. http://dx.doi.org/10 $.1111 / \mathrm{j} .1467-8624.2010 .01492 . \mathrm{x}$
Mercer, N., Keijsers, L., Crocetti, E., Branje, S., \& Meeus, W. (2016) Adolescent abstention from delinquency: Examining the mediating role of time spent with (delinquent) peers. Journal of Research on Adolescence, 26, 947-962. http://dx.doi.org/10.1111/jora.12246/pdf

Moffitt, T. E. (1993). Adolescence-limited and life-course-persistent antisocial behavior: A developmental taxonomy. Psychological Review, 100, 674-701. http://dx.doi.org/10.1037/0033-295X.100.4.674

Moffitt, T. E., Caspi, A., Harrington, H., \& Milne, B. J. (2002). Males on the life-course-persistent and adolescence-limited antisocial pathways: Follow-up at age 26 years. Development and Psychopathology, 14, 179-207. http://dx.doi.org/10.1017/S0954579402001104

Morsunbul, U., Crocetti, E., Cok, F., \& Meeus, W. (2014). Brief report: The Utrecht-Management of Identity Commitments Scale (U-MICS): gender and age measurement invariance and convergent validity of the Turkish version. Journal of Adolescence, 37, 799-805. http://dx.doi.org/ 10.1016/j.adolescence.2014.05.008

Muthén, L. K. and Muthén, B. O. (1998-12015). Mplus user's guide (7th ed.) Los Angeles, CA: Author.

Osgood, D. W., Wilson, J. K., O'Malley, P. M., Bachman, J. G., \& Johnston, L. D. (1996). Routine activities and individual deviant behavior. American Sociological Review, 61, 635-655. http://dx.doi.org/10 $.2307 / 2096397$

Papp, L. M. (2004). Capturing the interplay among within-and betweenperson processes using multilevel modeling techniques. Applied \& Preventive Psychology, 11, 115-124. http://dx.doi.org/10.1016/j.appsy.2004 .09 .002

Paternoster, R., McGloin, J. M., Nguyen, H., \& Thomas, K. J. (2013). The causal impact of exposure to deviant peers: An experimental investigation. Journal of Research in Crime and Delinquency, 50, 476-503. http://dx.doi.org/10.1177/0022427812444274

Pop, E. I., Negru-Subtirica, O., Crocetti, E., Opre, A., \& Meeus, W. (2016) On the interplay between academic achievement and educational identity: A longitudinal study. Journal of Adolescence, 47, 135-144. http:// dx.doi.org/10.1016/j.adolescence.2015.11.004

Quintana, S. M., \& Lapsley, D. K. (1987). Adolescent attachment and ego identity: A structural equations approach to the continuity of adaptation Journal of Adolescent Research, 2, 393-409. http://dx.doi.org/10.1177/ 074355488724007

Satorra, A., \& Bentler, P. M. (2001). A scaled difference chi-square test statistic for moment structure analysis. Psychometrika, 66, 507-514. http://dx.doi.org/10.1007/BF02296192

Schwartz, S. J., Mason, C. A., Pantin, H., \& Szapocznik, J. (2008). Effects of family functioning and identity confusion on substance use and sexual behavior in Hispanic immigrant early adolescents. Identity, 8, 107-124. http://dx.doi.org/10.1080/15283480801938440

Schwartz, S. J., Mason, C. A., Pantin, H., Wang, W., Brown, C. H., Campo A., \& Szapocznik, J. (2009). Relationships of social context and identity to problem behavior among high-risk Hispanic adolescents. Youth \& Society, 40, 541-570. http://dx.doi.org/10.1177/0044118X08327506

Schwartz, S. J., Pantin, H., Prado, G., Sullivan, S., \& Szapocznik, J. (2005). Family functioning, identity, and problem behavior in Hispanic immigrant early adolescents. The Journal of Early Adolescence, 25, 392-420. http://dx.doi.org/10.1177/0272431605279843

Sherif, M., \& Sherif, C. (1964). Reference groups exploration into conformity and deviation of adolescents. New York, NY: Harper \& Row.

Siennick, S. E., \& Staff, J. (2008). Explaining the educational deficits of delinquent youths. Criminology: An Interdisciplinary Journal, 46, 609635. http://dx.doi.org/10.1111/j.1745-9125.2008.00118.x

Soenens, B., Berzonsky, M. D., Vansteenkiste, M., Beyers, W., \& Goossens, L. (2005). Identity styles and causality orientations: In search of the motivational underpinnings of the identity exploration process. European Journal of Personality, 19, 427-442. http://dx.doi.org/10.1002/per .551 
van Doeselaar, L., Meeus, W., Koot, H. M., \& Branje, S. (2016). The role of best friends in educational identity formation in adolescence. Journal of Adolescence, 47, 28-37. http://dx.doi.org/10.1016/j.adolescence.2015 .12 .002

van Gelder, J. L., Hershfield, H. E., \& Nordgren, L. F. (2013). Vividness of the future self predicts delinquency. Psychological Science, 24, 974980. http://dx.doi.org/10.1177/0956797612465197

Verhulst, F. C., van der Ende, J., \& Koot, H. M. (1996). Handleiding voor de CBCL/4-18 [Manual for the Child Behavior Checklist/4-18]. Rotterdam, the Netherlands: Erasmus University and Department of Child and Adolescent Psychiatry, Sophia Children's Hospital.
Verhulst, F. C., van der Ende, J., \& Koot, H. M. (1997). Handleiding voor de Youth Self-Report (YSR) [Manual for the Youth Self-Report]. Rotterdam, the Netherlands: Erasmus University and Department of Child and Adolescent Psychiatry, Sophia Children's Hospital.

Warr, M. (2007). The tangled web: Delinquency, deception, and parental attachment. Journal of Youth and Adolescence, 36, 607-622. http://dx .doi.org/10.1007/s10964-006-9148-0

Received April 18, 2016

Revision received February 10, 2017

Accepted March 24, 2017 